\title{
THE COLCHESTER MEDICAL SOCIETY, 1774
}

by

WALTER RADCLIFFE*

The Colchester Medical Society was founded in 1774 by Robert Richardson Newell (1750-1814), a surgeon and apothecary practising in the town. It is the oldest provincial medical society in Great Britain. ${ }^{1}$ The earliest minute books have been lost, but the date is confirmed in Dr. Newell's obituary notice in the local press, ${ }^{2}$ and by the Medical Register for 1779, which lists all the members at that date, and includes this eulogy:

\begin{abstract}
In our Medical Tour through the several Counties it gives us a real pleasure to notice any institution that bid fair, not only to improve and extend the knowledge of medicine, and to diffuse an useful spirit of inquiry; but likewise to promote a state of harmony, amongst Medical Practitioners, which we have observed, and a worthy correspondent at Colchester joins with us in lamenting, is but too frequently interrupted in country towns. We are therefore happy to inform our readers that with these laudable views a MEDICAL SOCIETY was established at Colchester in 1774, which, from consisting at first of seven members only, has gradually, increased to nineteen, several of whom are resident in different towns of Essex and Suffolk. We regret however, on looking over this respectable list, that it does not include all the Practitioners at Colchester, by whom the institution deserves particularly to be encouraged, as tending to collect useful observations on the prevailing diseases of that town, and neighbourhood. The meetings of the Society are monthly, and the chair is filled by each member in rotation. Mr. Newell has acted as Secretary to the Society from the time of its establishment. In 1776 it became connected with the Humane Society of London, of which each member is an Assistant and a Director.8
\end{abstract}

There is a similar but shortened entry in the Medical Register for 1783, with a list of the members.4

Mr. Newell became the society's first secretary and treasurer, and remained so for the rest of his life. ${ }^{5} \mathrm{He}$ was the son of Robert Newell (1705-1766), a surgeon and apothecary practising at Harwich, and his wife Susannah, the daughter of John Richardson, an apothecary in Colchester. His mother died in 1764 at the age of forty-two, and his father two years later at the age of sixty-one, and he was then adopted by his grandfather, John Richardson, and may well have acted as his apprentice in his shop in Pelham's Lane in Colchester for a few years. Richardson died in $1768,{ }^{6}$ leaving property in the town to his grandson in the care of two trustees until he should come of age, when he was also to inherit his father's estate.

Whether he had any further medical training, and if so where, we do not know, but in November 1773 he married Miss Sally Hasell of Hadleigh in Suffolk, ${ }^{7}$ by whom he had twelve children, six boys and six girls. At first they occupied a house in the High Street, Colchester, but in the summer of 1780 they moved into a larger one in Head Street, putting their first house on the market to let. ${ }^{8}$

"Walter Radcliffe, M.A., M.B., B.Chir., "Longacre", 26 Welshwood Park Road, Colchester CO4 3HZ 


\title{
The Colchester Medical Society, 1774
}

It says much for Newell's tact, diplomacy and enthusiasm that at the age of twentyfour he was able to persuade his professional colleagues, all older than himself, to found the Colchester Medical Society. But, as if that was not enough, he was also instrumental in calling a meeting at Chelmsford on 30 October $1786,{ }^{\circ}$ which resulted in the foundation of the Essex and Hertfordshire Medical Benevolent Society "for the relief of distressed medical men, their wives, children and orphans". ${ }^{10}$ Newell was no doubt remembering his own parentless youth. The first president of this charity was Baron Thomas Dimsdale, M.D. (1712-1800), who had been given his title and a pension by the Empress Catherine II of Russia for his work in inoculating her and her courtiers against smallpox in 1768.

There is no doubt that Newell become one of the leading members of the medical profession in north Essex. At a dinner held at Berechurch near Colchester in 1801 he was toasted with the following rhyme:

\author{
Doctor $\mathrm{N}-\mathrm{l}$. \\ Roast beef and beef-tea are your best dietetics \\ Far better than bark, bolus, pills or emetics, \\ And good old Port wine is the best of all tinctures \\ Bracing nerves by relaxing our risible sphincters. ${ }^{11}$
}

In 1813 he was presented with a silver bowl by his Colchester colleagues in recognition of his services to the medical profession. ${ }^{12}$ This piece of plate was subsequently bequeathed to the Colchester Corporation by his grandson Major F. H. L. Newell, and it now forms an interesting part of the town's regalia. It was lent to the Medical Society for their bi-centenary exhibition in February 1974. Major Newell also left the corporation a small silhouette portrait of his grandfather, which has since been lost.

Newell died on 24 May 1814, and is buried in the churchyard of St. Mary-at-theWalls in Colchester. There is a memorial plaque in the church which describes him as a doctor of medicine, but none of the British universities has any record of him taking this degree. The same memorial also records the death of his wife Sally in 1825 at the age of seventy-three, and of one of their sons, Edward, also a surgeon, who died in 1800 at the early age of twenty-one.

All the other six members of the Medical Society in 1774 were older than Newell. The youngest, and one of the most interesting of them, was Henry Topping (17471819), who was only three years older, having been born in Cambridge in 1747. He was educated at Eton College, where he was a King's Scholar, and then gained a scholarship to Cambridge University. He was elected a life fellow of King's College, Cambridge, in 1770, two years before he took his B.A. degree, and he did not take his M.D. degree until 1782. ${ }^{13}$ Apparently he preferred to practise medicine in Colchester, instead of leading an academic life in Cambridge. He died in 1819, following a fall from his horse.

Colin Hossack (d. 1782) had the most distinguished career of the founder members of the society. He had graduated M.D. at Edinburgh, and was the author of $A n$ abridgement of Van Swieten's commentaries on Boerhaave, published in 1773. He had been personal physician to H.R.H. Frederick, Prince of Wales, the father of George III. The prince had died in 1751, and Dr. Hossack then left London, for he became 


\section{Walter Radcliffe}

mayor of Sudbury in 1753 . He was practising in Colchester before $1764,{ }^{14}$ but eventually retired to live in Braintree, where he died in $1782 .{ }^{15}$

Jordan Harris Lisle (d. 1788), was a descendant of Sir George Lisle, who had been one of the commanders of the Colchester garrison during the siege of the town in 1648. He was in practice in Colchester as an apothecary in $1753,{ }^{16}$ and he became mayor of Colchester in 1769. In 1781 he sold "... his old accustomed Apothecary's shop, with the fixtures, drugs etc., the owner retiring from business." ${ }^{17} \mathrm{He}$ retired to Copdock, near Ipswich, where he died in 1788.

Cater Day (d. 1799) practised as a surgeon, and had been apprenticed to Robert Courthope Sims of Dunmow in 1754 for the sum of $£ 105 . .^{18} \mathrm{He}$ was a leading member of the Quaker community in Colchester, and also renowned as a keen sportsman. He was an enthusiastic inoculator against the smallpox. ${ }^{10}$ In 1782 he was adjudged bankrupt, ${ }^{20}$ and his house was put up for sale to pay his debts. ${ }^{21} \mathrm{He}$ died in 1799 when he ". . . accidentally fell into the river near Hythe bridge, and was drowned". ${ }^{22}$

Joseph Stapleton (1740-1797) practised as a surgeon and apothecary. He had taken his M.D. degree in Edinburgh in 1767 with a thesis on "Phthisi pulmonali". In February 1797 he became very ill, and was unable to carry on with his practice, and he engaged a Mr. S. Philbrick to be his assistant. ${ }^{23}$ Stapleton was a leading nonconformist in Colchester, and when he died in May, three months later, at the age of fifty-seven, he was buried in Lion Walk.

Mr. Philbrick joined the medical society, and his son, S. A. Philbrick, became president of the society in 1856.

Robert Sterling (1724-1787), whose name was omitted from the list of members in the 1799 edition of the Medical Register, but included in the 1783 edition, practised as a surgeon and man-midwife in the High Street. He was elected a Fellow of the Royal Society on the recommendation of Charles Gray, the member of parliament for Colchester, and others for his knowledge of mathematics. He died in 1787 at the age of sixty-three. ${ }^{24}$

The society soon began to attract members from outside the town, and the first two country members were John Rogers of Manningtree and William Fairclough of Nayland in Suffolk, both of whom joined in 1775. Within five years the society had members in East Bergholt, Holbrook, Long Melford, Coggeshall, Wivenhoe, and even one thirty-six miles away at Saxmundham.

The most distinguished of the new members was Dr. John Coakley Lettsom (17441815), who was elected in May, $1786 .{ }^{25} \mathrm{He}$ was the founder of the Medical Society of London in 1773, which may well have been a model for Newell's society in Colchester. He was a leading member of the Quaker community, an ardent supporter of the campaign for prison reform, and an enthusiastic advocate for vaccination, in place of the inoculation of smallpox.

It was not long before the new spirit of co-operation between the doctors came to the notice of the public. One of their first corporate acts was to publish a free leaflet on the resuscitation of the apparently drowned, but what these instructions were is a matter for conjecture, since no copy is known to exist. In the summer of 1775 the Ipswich Journal recorded an example of their efforts in resuscitation as follows: 


\section{The Colchester Medical Society, 1774}

Colchester, July 1775. On Wednesday evening about 7 o'clock as Mr. Thomas Thorp, about 24 years of age, eldest son of Mr. Thorp, watchmaker, in this town, was bathing in the river with another person, he was carried down the current out of his depth and drowned. . . . Some of the gentlemen of the Colchester Medical Society, (agreeable to their published directions for the recovery of such unhappy persons) used every method to recover him, but we apprehend their endeavours were rendered abortive, by reason of the length of time he was under water, and a previous ill state of health, occasioned by a disorder of his lungs. N.B. The above mentioned printed directions may be had gratis, of W. Keymer, bookseller, in Colchester. ${ }^{20}$

It may well have been this incident which prompted Newell to write to the newlyformed Humane Society of London for their help. The Humane Society had been founded in 1774 by Dr. William Hawes (1736-1808), and Dr. Thomas Cogan (17361818) as the Society for the Recovery of the Apparently Drowned. Their minute book records that, at a meeting held at the London Coffee House on 30 January 1776:

Mr. Hawes then reported that a Society at Colchester had applied to this Society by a letter to him requesting of us to extend our rewards to that town and to enforce their requests they had undertaken to raise by subscription in the town sufficient to defray expenses attending. ${ }^{27}$

This proposal was accepted at the annual general meeting of the Humane Society in May, and in the following February the secretary was able to report to the committee that the Colchester Medical Society had collected twenty guineas. ${ }^{28}$ In return for this financial help, the Humane Society elected all the members of the Colchester Medical Society at that date as "Directors and Medical Assistants", with the addition of two lay members, Charles Gray, M.P., and the Rev. Harry Hankey, the rector of East Bergholt in Suffolk, a riverside parish which included Flatford. ${ }^{20}$

It was also reported to the committee of the Humane Society in May 1777, that "a letter from Mr. Newell, secretary to the Medical Society at Colchester, having been read to the society, in which their society desired to have an apparatus according to the plans of the London Society, resolved that an apparatus be sent to Mr. Newell for the use of the Medical Society of Colchester".30

This apparatus was very soon put to use, for, in the annual report for the same year, Newell himself received a commendation for rescuing his own maidservant, who had fallen down a well. In this he was assisted by his colleagues Robert Sterling and Cater Day. It seems clear that the apparatus was a fumigator, which was a small pair of bellows and a tube, by which means they blew tobacco smoke into the rectum. It is not surprising that, as Newell recorded, the poor girl ". . . next day complained of a great sense of weight and fullness in the intestines, and I therefore gave her a gentle purge, which produced good effects."31

The tobacco smoke enema had been described and illustrated by John Woodall (1569-1643), in a book he wrote for the use of naval surgeons, which he called The surgeon's mate. ${ }^{32}$ The Humane Society recommended its use, as well as a bellows to blow air into the mouth, but Lettsom, who was opposed to the use of tobacco for this purpose, did all he could to discourage its use when he took over the compilation of the Humane Society's annual reports in 1808, after the death of Dr. Hawes. 23

One of the earliest recipients of the Humane Society's medal was William Fairclough, of Nayland, who has already been mentioned as one of the first country 


\section{Walter Radcliffe}

members of the Medical Society. This was awarded for his resuscitation of the fifteen-month-old child of James and Elizabeth Bacon on 24 March 1777. In writing his report of the case, he added, "The assistants were not only satisfied but very thankful for some drink that I supplied them with, therefore no expence was incurred on their account." 34

But the Medical Society's team-work was not only confined to resuscitation, for the Ipswich Journal reported that in May 1783, "A child of four was cut for the stone by some gentlemen of the Medical Society, and is likely to do well". ${ }^{.5}$ Stone in the bladder was extraordinarily common in children under the age of ten in the eighteenth century, especially in East Anglia, but the reasons for this are still somewhat obscure. ${ }^{36}$

Another example of this team-work was recorded by Sir Astley Cooper, when he published a letter from John Rogers of Manningtree, who may well have been one of his former pupils. This recounted the history of William Dawson, aged thirty-four, who dislocated his hip joint in a drunken brawl while celebrating harvest-home in 1811. Rogers called in the help of his neighbours Roger Nunn of Colchester and William Travis of East Bergholt. On Sunday 30 August, fifteen days after the accident, they succeeded in reducing the dislocation ". . . after ten or twelve minutes' gradual extension ....". Rogers added that "Preparatory to commencing the operation, we took thirty ounces of blood from the arm ad deliquium, and afterwards, while fixing the pullies, etc., we gave four grains of tartarized antimony at intervals to produce nausea". The patient was able to get about on crutches after about a fortnight. ${ }^{37}$

All three of these surgeons were members of the Medical Society, and they all had sons who followed them in their practices, and who joined the society in due course. At this time there was no hospital in Colchester, but when the present Essex County Hospital was opened there in 1820, Roger Nunn became one of the first three surgeons to join the staff.

There is a short account of the society in Thomas Cromwell's History of Colchester, published in 1825 . He wrote that:

It has four meetings in the year, in April, June August and October. Medical or surgical patients, (whose cases are deemed obscure or difficult), attend on these occasions, being introduced by a member, for the purpose of obtaining the opinion and advice of the medical gentlemen assembled, and their cases are subsequently discussed and prescribed for; memoranda of them being entered in a minute book kept for that purpose. A proportion of the funds is appropriated to the purchase of books, which circulate through the society. The subscription is one guinea entrance and half a guinea per annum. The present number of ordinary and corresponding members is between twenty and thirty, and its officers are as follows;

Dr. Mackintosh, President.

Mr. Gretton, Treasurer.

Mr. Partridge, Secretary.88

Dr. R. D. Mackintosh was one of the first two physicians to be appointed to the staff of the Essex County Hospital in 1820.

The earliest existing minute book covers the years from 1833 to 1856 . It is a small octavo booklet, and in most instances records very little more than the date of meeting, the names of members present, and the election of officers at the annual meeting. Sometimes there is a note of any important case which was shown and discussed, and sometimes there is added a list of books purchased for the library. 
But occasionally special meetings were called to discuss matters of professional behaviour, and these were recorded at some length. One such occasion was on 6 December 1843, when allegations of professional misconduct by a member were argued at some length, but the only action taken was to instruct the secretary to write him a letter of censure. He was not asked to resign, and remained a member for several years, and indeed became mayor of Colchester on four occasions. It may have been this incident which led to a resolution being passed at a subsequent meeting that in future at least fourteen days' notice must be given to all the parties concerned and to every member of the society of any such allegations of professional misconduct.

In 1852 the society passed a resolution that no member shall practise homeopathy, or associate with any homeopathic practitioner in a professional capacity.

The establishment of the General Medical Council in 1858 brought this side of the society's activities to an end.

At some time in the mid-nineteenth century it became the custom for members attending meetings to dine together afterwards, the rule being that the chairman had to "call for the bill at nine o'clock". The meetings then became social gatherings, and members were permitted to smoke, though objections to this practice are recorded in the minute book, without any firm decision being reached. For several years there was also a rule that absentee members could be fined five shillings, the proceeds of this fund to be spent on the dinner, but this rule was subsequently rescinded, perhaps because the defaulters tended to send in their resignations, rather than pay up their arrears.

The formation of a library was one of the earliest objects of the society, but it was more of a circulating book club than a permanent collection. This may have been because of the difficulties of finding a place to store the books. For some years they were kept in an upstairs room hired from a local bookseller. Books and periodicals were purchased at the request of members, and they were put up for sale after each annual general meeting, which was known as the Anniversary meeting. But in 1843 the beginnings of a more permanent collection were made, when the society subscribed to the Sydenham Society for its reprints of medical classics, and some of these are still in the library. Other important books were also retained: for example a copy of the life and works of John Hunter was bought for the society at the sale in 1861 for the sum of "one pound and twelve shilling only."

The first library committee was elected in 1855 , and the first honorary librarian in 1888. In 1907, when the late Dr. Philip Laver held the office, the title was changed to "Librarian and Keeper of the Archives", presumably in recognition of his research into the history of the society. His manuscript notes have been invaluable in preparing this article.

The society today draws its membership from a much smaller area than it did two hundred years ago, and yet the total membership is now over two hundred. Medicine and surgery have expanded and diversified to an extent which would have been inconceivable in the eighteenth century. In bringing all these branches of the profession together regularly, the Colchester Medical Society is faithfully carrying out the original intentions of its founder Dr. Robert Richardson Newell, and his colleagues. 


\section{Walter Radcliffe}

\section{ACKNOWLEDGEMENTS}

I wish to record my thanks to Dr. Phyllis Clendon and to Mr. K. M. Mackenzie, F.R.C.O.G., for permission to use material from their presidential addresses to the society; to Mr. John Bensusan-Butt for permission to use his researches into the files of the Ipswich Journal and the records of the Royal Humane Society; and to Mr. J. M. Leadbitter, for permission to quote from the Royal Humane Society's minute book. I would especially record my thanks to Dr. John Penfold for his helpful criticism in preparing this article for the press.

\section{SUMMARY}

The Colchester Medical Society was founded by a young apothecary, Robert Richardson Newell, in 1774, and is the oldest surviving medical society in England, with the exception of the Medical Society of London, which was founded in the previous year. The earliest minute book has been lost, but the date is confirmed in the Medical Register for 1779, which also lists the names of the members.

At the meetings of the society members were encouraged to present difficult or interesting cases for diagnosis and discussion. The society was from the first interested in the recovery of persons apparently drowned, and published instructions to the public for this purpose. It also joined the Humane Society of London. A medical lending library was established, and any surplus volumes were sold to the members by auction at the "Anniversary" meeting each year.

Until the establishment of the General Medical Council in 1858, the society took its own members to task for unprofessional conduct.

The society today has over 200 members, and holds regular meetings in Colchester for the discussion of medical and allied subjects, and social activities.

\section{REFERENCES}

1. A. Batty Shaw, 'The oldest medical societies in Great Britain', Med. Hist., 1968, 12: 232-244.

2. Ipswich Journal, 28 May 1814.

3. The Medical Register for the year 1779, London, J Murray, 1779, pp. 81 and 82

4. The Medical Register for the year 1783, London, J. Murray, 1783, pp. 66 and 67.

5. Ipswich Journal, 28 May 1814.

6. Ibid., 28 May 1768.

7. Ibid., 19 November 1773.

8. Ibid., 9 July $\mathbf{1 7 8 0 .}$

9. Essex Chronicle, 20 and 27 October 1786.

10. Ibid., 3 and 10 November 1786.

11. Ipswich Journal, 31 January 1801.

12. Ibid., 28 May 1814.

13. J. A. Venn, Alumni Cantabrigiensis, Cambridge, Cambridge University Press, 1954, part 2, vol. 6, p. 209.

14. Ipswich Journal, 10 March 1764.

15. Ibid., 21 December 1782.

16. Ibid., 7 April 1753.

17. Ibid., 23 June 1781.

18. Note supplied by John Bensusan-Butt from the register of apprentices in the Public Record Office.

19. Ipswich Journal, 27 June 1767.

20. Ibid., 26 January 1782. 
The Colchester Medical Society, 1774

21. Ibid., 8 June 1782.

22. Ibid., 12 October 1799.

23. Ibid., 18 February 1797.

24. Ibid., 15 December 1787.

25. Ibid., 3 June 1786.

26. Ibid., 22 July 1775.

27. Royal Humane Society. Minutes. 30 January 1776.

28. Ibid., 26 February 1777.

29. Royal Humane Society's Annual Report, 1777, [pub. 1778].

30. Royal Humane Society, Minutes. 5 May 1777.

31. Op. cit. note 29 above, case 149.

32. John Woodall, The surgeon's mate, 2nd ed., London, 1639, pp. 27-31.

33. J. Johnston Abraham, Lettsom, his life, times, friends and descendants, London, Wm. Heinemann, 1933, p. 147n.

34. Op. cit., note 29 above, case 148.

35. Ipswich Journal, 31 May 1783.

36. A. Batty Shaw, 'The Norwich school of lithotomy', Med. Hist., 1970, 14: 243-245.

37. Astley Cooper and Benjamin Travers, Surgical essays, part 2, London, Longman Hurst, 1819, pp. 10-13.

38. Thomas Cromwell, History and description of the ancient town and borough of Colchester in Essex, London, Robert Jennings, 1825, vol. 2, pp. 343-344. 